\author{
Pawel Lula ${ }^{1}$ \\ Renata Oczkowska \\ Anna Kovaleva \\ Sylwia Wiśniewska
}

\section{METHODS OF COMPETENCY SCHEMA IDENTIFICATION AND EVALUATION}

Abstract: Methods of competency schema identification form the main topic of the paper. The survey of literature on the significance of competences on labour markets justifies the need for searching new methods and tools for performing labour market analysis. The authors propose competency schemas as a new tool for analysis competency demand existing on a given market. It seems that competency schemas can outperform competency profiles with respect to the scope of information which they can present. After presenting competency schemas concept, their application to analysis the situation on Polish labour market was discussed. The conclusions are formulated in the last part of the paper.

Keywords: labour market, competencies, competency schemas.

\section{Introduction}

The changes on the labour market is progressively faster, which also means a fast outdating of the existing competencies and a growing demand for new competencies. It is principally important for the company competitiveness to monitor the demand for competencies, containing identification of trends concerning changes of the demand for labour. It thus becomes significant to develop possibilities of identifying the employer demand for competencies and the supply of competencies (Lula et al, 2019).

The subject literature includes numerous definitions of the concept of competencies. The diversity of approaches results mainly from the fact that this issue is analysed by specialists representing dissimilar scientific disciplines like management, psychology or sociology. The initial concept developed by McClelland (1973) referred to competencies as components of performance related with "clusters of life outcomes". This approach describes competencies as any psychological or behavioural attributes connected with success.

Studies on the subject literature show that presently can be indicated two approaches, according to which the concept of employee competencies is comprehended. According to the first approach, competencies are understood as people's characteristics, which account for a basis of desired behaviour at work, allowing them to achieve planned results. Competencies are therefore defined as the ability to implement detailed patterns of behaviour. According to the second approach, competencies are defined as characteristics of a professional position. This interpretation describes competencies as the ability to effectively perform professional duties in compliance with standards established by the organisation or to achieve desired results (Whiddett, Hollyforde, 2003).

From a macroeconomic perspective, employee competencies are measured in numerous studies. Examples contain OECD's Survey of Adult Skills from the

\footnotetext{
${ }^{1}$ Corresponding author: Paweł Lula

Email: pawel.lula@uek.krakow.pl
} 
Program of International Assessment of Adult Competences and country specific student test scores. These studies afford measures of the supply of competences on the labour market. Nevertheless, companies' demand for competencies and competency mismatch are measured only from a microeconomic perspective while similar studies are lacking from a macroeconomic perspective (Pater et al, 2018).

In general, modern companies are interested in four group of the core competencies such as intellectual, professional, personal and interpersonal (Cichoń M., Piotrowska I., 2018). The company's strategic planning also has to be taken into account to make an analysis of labour demand (FernándezHuerga E., 2019).

The labour perspective in terms of demanding of competences is presented in different researches conducted in the relevance to various countries and fields of economy. In this regard it's worth to mention the studies devoted to analysis of matching labour market demands with competences of graduates. One of the methodological approach is aimed to analyse the list of competences presented in job advertisements (Suarta I. M. et al, 2018; Olawale, 2015; Dunbar K., et al., 2016; Messum D. et al., 2016). Another one method to recognise competence requested by companies is ontology-guided job market demand analysis (Sibarani, E. et al., 2017).

Hovewer, the lack of connection between competencies is appeared in these observations of employability which means a set of achievements, understandings and personal qualities that increase the probability of getting a job and succeeding in a chosen profession (Cichoń M., Piotrowska I., 2018).

University business cooperation is considered as the one of the instrument to overcome the gap between competencies acquired by graduates of universities and company's demand (Dávila C. et al, 2016).

Nowadays in the digital era employers are looking for highly qualifies graduates but saving time and money for this search. That's why e-portfolio for instance is considered as the useful tool for former students and companies due to this format promote the first ones and keep efforts of the last (Malita L., 2009).

Moreover, the misperception of links between market demand of competencies and skills of graduates is presented by both sides as labour market and universities. So it's valued to evaluate this mismatching and additionally to predict the competencies demanded by companies in the future.

To overcome limitations related to described methodological approaches, the authors of this paper formulate the thesis that the analysis of possessed or required competencies shouldn't be carried out separately for each competency, but should always involve a certain set of them taken together. In the given set of competencies, the importance of each of them can be diverse, and this aspect can be expressed in the model by different weights assigned to them. Also, the character and the strength of relationships between consecutive competencies may be varied. Taking thesis formulated above as a starting point, the authors uses the term "competency schema" understood as a set of interrelated competencies together with information defining their significance and the nature and strength of links between them (Lula et al, 2019).

\section{Competency schemas}

This section presents a competency schema concept and procedures used for its building, normalization and comparison.

\subsection{Competency schema concept}

The competency schema concept was introduced in (Lula et al, 2019). It can be defined as a set competencies and a set of relations between them, together with the 
information about the importance of every competency and the importance of every relationship between any two competencies.

The competency schema can be represented by a weighted graph, in which nodes represent competencies and edges represent relations between two competencies. Weights are assigned to nodes (and represent competency importance) and to edges (they represent the importance of relations between competencies). We should assume that nodes also have labels identifying competencies assigned to them.

It should be stated that a graph representing a competency schema should be connected. It means that every two competencies are connected by a path (in other words, that a path connecting nodes representing these competencies exists and all weights assigned to this path are greater than zero).

Let's assume that $\boldsymbol{C}$ is a set of competencies:

$$
\boldsymbol{C}=\left\{C_{1}, C_{2}, \ldots, C_{M}\right\} .
$$

In this context, a competency schema can be defined as a weighted graph represented by a adjacency matrix $\boldsymbol{G}$ :

$$
\begin{gathered}
\boldsymbol{G}=\left[g_{i j}\right] \\
i, j=1, \ldots, M
\end{gathered}
$$

where diagonal elements $g_{i i}$ inform about the importance of the $i$-th competency, and off-diagonal elements $g_{i j}$ describe a strength of relations between competencies $C_{i}$ and $C_{j}$.

Competency schemas can be useful in many applications. Among them, the following examples of usage can be enumerated:

- competency schemas can be used for evaluating the distance between the current situation on the labour market and its desirable state. This measure can be treated as an indicator of quality for competency development,

- analysis territorial or sectorial diversity of competencies,
- analysis of the content of various study or training programs and similarities between them.

\subsection{Competency schema building}

We will consider a set of competencies:

$$
\boldsymbol{C}=\left\{C_{1}, C_{2}, \ldots, C_{M}\right\}
$$

and a set of objects to which competencies are assigned (e.g. job offers, job positions, members of staff, candidates for employment, responders):

$$
\boldsymbol{O}=\left\{O_{1}, O_{2}, \ldots, O_{N}\right\}
$$

The analysis of offers enables to define the object-competency matrix $\boldsymbol{M}$ :

$$
\begin{gathered}
\boldsymbol{M}=\left[m_{i j}\right] \\
i=1, \ldots, N ; j=1, \ldots, M
\end{gathered}
$$

where $m_{i j}=1$ if the $j$-th competency is mentioned in the context of the $i$-th object, and $m_{i j}=0$ if the information about the $j$-th competency does not appear in the context of the $i$-th object.

We assume that two competencies $C_{i}$ and $C_{j}$ are connected if they appear in the context of the same object $O_{k}$. Connections between competencies are represented by the competency co-occurrence graph which has weighted and undirected character and is represented by the adjacency matrix $\boldsymbol{R}$ :

$$
\boldsymbol{R}=\left[r_{i j}\right]
$$

where $r_{i i}$ element informs how many times the $C_{i}$ competency is mentioned in the context of the given data set $\boldsymbol{O}$, and $r_{i j}$ (where $i \neq j$ ) shows how many times competencies $C_{i}$ and $C_{j}$ appeared together in the context of the same object.

Some competencies can be very infrequent and have insignificant character in a given data set. Therefore competencies with weights $r_{i i}<t$ may be removed from the $\boldsymbol{R}$ graph (by removing $i$-th row and the $i$-th column).

Weights assigned to edges in the $\boldsymbol{R}$ graph 
usually have various values which allows to identify areas strongly and weakly connected and, in the next step, to identify communities in the $\boldsymbol{R}$ graph (Liu et al, 2014). Decomposition of the $\boldsymbol{R}$ can be performed with the use of several algorithms. Among them the Girvan-Newman method, greedy optimization of modularity and graph partitioning algorithm are the most popular. The detailed description of community detection algorithms can be found in (Fortunato, 2010). It can be assumed that the process of community identification allows to recognize communities $\boldsymbol{G}_{1}, \ldots, \boldsymbol{G}_{K}$ which can have overlapping or non-overlapping character.

In view of the above, the competency schema can be defined as a community structure $\boldsymbol{G}$ identified in the competency cooccurrence graph $\boldsymbol{R}$.

\subsection{Competency schema normalization}

Original values appearing in competency schema $\boldsymbol{G}$ represent the number of occurrences for every competency ( $g_{i i}$ elements) or the number of simultaneous occurrences of every two competencies $\left(g_{i j}\right.$ elements). The use of original values may cause problems with competency schemas comparison. It seems that competency schema normalization may at least partly eliminate problems occurring during comparison process. Normalization can be defined as a transformation of weights of competency schema allowing to perform the comparison of two or more schemas.

The normalization of diagonal elements of a competency schema $\boldsymbol{G}$ can be conducted by the use of the following formula:

$$
h_{i i}=\frac{g_{i i}}{\sum_{k=1}^{N} g_{k k}}
$$

Diagonal values after normalization show the structure of competencies and the sum is equal to one.

Off-diagonal elements can be transformed with the use of the formula:

$$
h_{i j}=\frac{g_{i j}}{\sum_{\substack{k=1 \\ k \neq i}}^{N} g_{i k}}
$$

This formula normalizes connections adjacent to every competency separately. Alternatively, the formula:

$$
h_{i j}=\frac{g_{i j}}{\sum_{k=1}^{N} \sum_{\substack{l=1 \\ l \neq k}}^{N} g_{k l}}
$$

can be used. In this case the scaling operation is performed with regard to all connections existing in a given schema.

\subsection{Competency schema comparison}

As it was indicated above, very often comparison process ought to be preceded by normalization procedure. In such a case in formulas presented below weights taken from original competency schemas $\left(g_{i j}\right)$ should be replaced by their equivalents from normalized structure $\left(h_{i j}\right)$.

Subtraction of corresponding weights from two competency schemas forms the simplest form of their comparison:

$$
d_{i j}=g_{i j}^{I}-g_{i j}^{I I}
$$

Using this formula, a dominance of a given element over its counterpart is represented by a sign of a result of a subtraction operation.

As an alternative for subtraction operation, a similarity between two corresponding weights can be calculated. It seems that a similarity measure based on a Jaccard coefficient can be used:

$$
s_{i j}=\frac{\min \left(g_{i j}^{I}, g_{i j}^{I I}\right)}{\max \left(g_{i j}^{I}, g_{i j}^{I I}\right)}
$$

The result $s_{i j}$ belongs to a range $[0 ;+1]$ and values closer to one indicate greater similarity. 


\section{Intermational Cualily Conference}

\section{Competency schemas on Polish labour market}

The analysis of job offers published online in the portal https://www.pracuj.pl/ allowed to build the competency co-occurrence graph for Polish labour market. With the use of exploratory text analysis techniques five thousand of job offers were analysed and required competencies were identified. During the analysis, the system presented in (Lula, P. et al., 2017) was used.

First the competency co-occurrence graph $\boldsymbol{R}$ for Polish labour market was build. It is presented in Figure 1. The importance of competencies is represented by a diameter of nodes and the importance of relations by the darkness of edges.

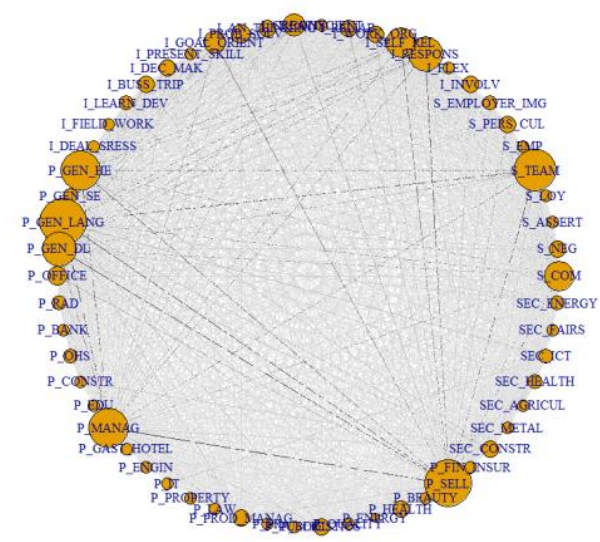

Figure 1. Competency co-occurrence graph for Polish labour market

Community detection based on greedy optimization of modularity algorithm allowed to identify four main competency schemas. Figure 2 shows one them which is related to construction sector.

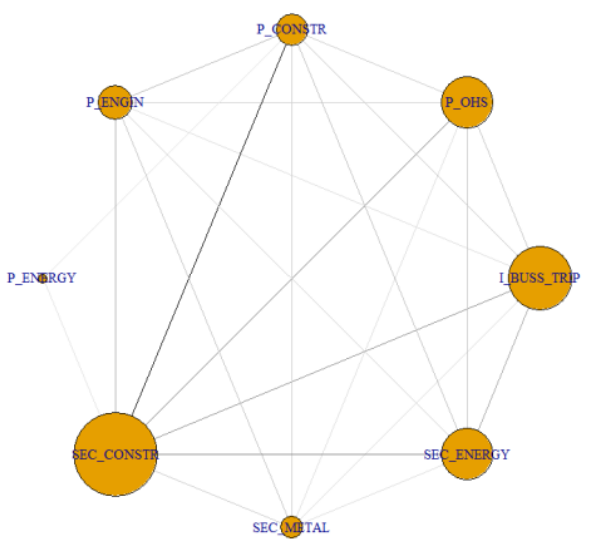

Figure 2. Competency schema identified on Polish labour market

It can be noticed that for the competency schema presented in Figure 2, the contribution of two the most significant competencies form almost $50 \%$ of the whole mass of competencies (Table 1).

Table 1. The distribution of competences in the competency schema presented in Figure 1.

\begin{tabular}{|l|c|c|}
\hline \multicolumn{1}{|c|}{ Node } & Weight & Cum. w. \\
\hline SEC_CONSTR & 0.278 & 0.278 \\
\hline I_BUSS_TRIP & 0.200 & 0.478 \\
\hline P_OHS & 0.154 & 0.632 \\
\hline SEC_ENERGY & 0.152 & 0.783 \\
\hline P_ENGIN & 0.091 & 0.874 \\
\hline P_CONSTR & 0.083 & 0.958 \\
\hline SEC_METAL & 0.041 & 0.998 \\
\hline P_ENERGY & 0.002 & 1.000 \\
\hline
\end{tabular}

Competencies are presenting in descending order of their importance. The column "Cum. w." (cumulative weights) shows for every competency the meaning of a given competency and all preceding ones.

The Gini coefficient can be used as a measure of the inequality of competency importance. Having eight competencies, the minimal value of Gini coefficient (that is 0 ) will be obtained when the contribution of every competency is the same and equal to $\frac{1}{8}$. On the other hand, the maximal value of its 
coefficient (that is 1) we will obtain if the significance of one competence is equal to 1 , and for all other competencies their significance will be equal 0 . In the case of a competency schema presented in Figure 2 the Gini coefficient is equal to 0.4289 .

In the similar way the weights of a competency schema can be analysed. For a competency schema presented in Figure 2, the weights are presented in Table 2.

Table 2. The distribution of weights in the competency schema presented in Figure 1.

\begin{tabular}{|l|l|l|}
\hline Edge & Weight & $\begin{array}{l}\text { Cum. } \\
\text { w. }\end{array}$ \\
\hline $\begin{array}{l}\text { P_CONSTR|SEC_CONST } \\
\text { R }\end{array}$ & 0.2200 & 0.2200 \\
\hline P_OHS|SEC_CONSTR & 0.1062 & 0.3263 \\
\hline $\begin{array}{l}\text { SEC_CONSTR|SEC_ENE } \\
\text { RGY }\end{array}$ & 0.1032 & 0.4294 \\
\hline $\begin{array}{l}\text { I_BUSS_TRIP|SEC_CONS } \\
\text { TR }\end{array}$ & 0.0835 & 0.5129 \\
\hline $\begin{array}{l}\text { I_BUSS_TRIP|SEC_ENER } \\
\text { GY }\end{array}$ & 0.0698 & 0.5827 \\
\hline P_ENGIN|SEC_CONSTR & 0.0607 & 0.6434 \\
\hline P_CONSTR|P_ENGIN & 0.0455 & 0.6889 \\
\hline $\begin{array}{l}\text { P_CONSTR|SEC_ENERG } \\
\text { Y }\end{array}$ & 0.0364 & 0.7253 \\
\hline P_ENGIN|SEC_METAL & 0.0349 & 0.7602 \\
\hline I_BUSS_TRIP|P_CONSTR & 0.0334 & 0.7936 \\
\hline I_BUSS_TRIP|P_OHS & 0.0319 & 0.8255 \\
\hline P_OHS|SEC_ENERGY & 0.0303 & 0.8558 \\
\hline P_OHS|P_CONSTR & 0.0258 & 0.8816 \\
\hline $\begin{array}{l}\text { SEC_CONSTR|SEC_MET } \\
\text { AL }\end{array}$ & 0.0243 & 0.9059 \\
\hline P_CONSTR|SEC_METAL & 0.0212 & 0.9272 \\
\hline P_ENGIN|SEC_ENERGY & 0.0197 & 0.9469 \\
\hline P_OHS|P_ENGIN & 0.0167 & 0.9636 \\
\hline $\begin{array}{l}\text { I_BUSS_TRIP|SEC_MET } \\
\text { AL }\end{array}$ & 0.0106 & 0.9742 \\
\hline I_BUSS_TRIP|P_ENGIN & 0.0076 & 0.9818 \\
\hline P_OHS|SEC_METAL & 0.0076 & 0.9894 \\
\hline $\begin{array}{l}\text { SEC_METAL|SEC_ENER } \\
\text { GY }\end{array}$ & 0.0076 & 0.9970 \\
\hline
\end{tabular}

\begin{tabular}{|l|l|l|}
\hline Edge & Weight & $\begin{array}{l}\text { Cum. } \\
\text { w. }\end{array}$ \\
\hline P_CONSTR|P_ENERGY & 0.0015 & 0.9985 \\
\hline $\begin{array}{l}\text { P_ENERGY|SEC_CONST } \\
\text { R }\end{array}$ & 0.0015 & 1.0000 \\
\hline
\end{tabular}

In a given schema there are 23 connections. Taking into account that the maximum number of connections for the analysed schema is equal to $\frac{7 * 8}{2}=28$, the competency schema density is rather high and equal to $\frac{23}{28}=0.8214$. The Gini coefficient calculated for weights is equal 0.6245 (during calculations five zero weights were included) and reflects a high inequality of weights. It is worth to notice that four the most significant weights represent more than 50\% of all relations in the schema.

\section{Conclusion}

The results showed in the paper show that the concept of competency schema can be used for representation of crucial patterns existing on labour markets. Schemas may give a detailed insight into requirements of employers and can be helpful for estimating competency gap or design study or training programs appropriate for the needs of the labour market.

All calculations presented in the paper were performed by the authors with the use of $R$ program.

Acknowledgment: The Project has been financed by the Ministry of Science and Higher Education within "Regional Initiative of Excellence" Programme for 2019-2022. Project no.: 021/RID/2018/19. Total financing: 11897 131,40 PLN. 


\section{Intermational Qualilty Conference}

References:

Cichoń M., Piotrowska I. (2018). Level of academic and didactic competencies among students as a measure to evaluate geographical education and preparation of students for the demands of the modern labour market. Quaestiones Geographicae, Sciendo, 37(1), 73-86.

Dávila, C.D., Mora, J.G., Pérez, P.J. and Vila, L.E. (2016) Enhancing the Development of Competencies: The Role of UBC. European Journal of Education, 51, 10-24. http://dx.doi.org/10.1111/ejed.12162

Dunbar, K., Laing, G., \& Wynder, M. (2016). A content analysis of accounting job advertisements: Skill requirements for graduates. e-Journal of Business Education \& Scholarship of Teaching, 10(1): $58-72$.

Fernández-Huerga E. (2019) The Labour Demand of Firms: An Alternative Conception Based on the Capabilities Approach, Cambridge Journal of Economics, 43 (1), 3760, https://doi.org/10.1093/cje/bey013

Fortunato S., (2010), Community detection in graphs, https://arxiv.org/pdf/0906.0612.pdf

Liu R., Feng S., Shi R., \& Guo W. (2014), Weighted graph clustering for community detection of large social networks, Procedia Computer Science, 31, 85-94.

Lula, P., Wiśniewska, S., \& Wójcik K., (2019). Analysis of the demand for competencies on the Polish labour market in the context of Industry 4.0. The 13th Professor Aleksander Zelias International Conference on Modelling and Forecasting of Socio-Economic Phenomena. Conference Proceedings. Cracow: Foundation of the Cracow University of Economics.

Lula, P., Oczkowska, R., Wiśniewska, S., Wójcik, K., (2018). Ontology-based System for Automatic Analysis of Job Offers. Information Technology for Practice 2018. Ostrava: VSB-Technical University, 205-212.

Malita L. (2009) E-portfolios in an educational and ocupational context. Procedia - Social and Behavioral Sciences, 1 (1), 2312-2316.

McClelland, D. (1973). Testing for competence rather than intelligence. American Psychologist, 28, 1-14.

Messum, D., Wilkes, L., Peters, K., \& Jackson, D. (2016). Content analysis of vacancy advertisements for employability skills: Challenges and opportunities for informing curriculum development. Journal of Teaching and Learning for Graduate Employability, 6 (1): $72-86$.

Olawale, Y. (2015). The employability skills provision within a construction Project Management Degree programme In: Raidén, A B and Aboagye-Nimo, E (Eds) Procs 31 Annual ARCOM Conference, 7-9 September 2015, Lincoln, UK, Association of Researchers in Construction Management, 959-968.

Pater, R., Szkola, J., \& Kozak, M. (2018). A method for measuring detailed demand for workers' competences. Economics, 11(83),1-24.

Sibarani, E.M., Scerri, S., Morales, C., Auer, S., Collarana, D. (2017) Ontology-guided job market demand analysis: a cross-sectional study for the data science field. Proceedings of the 13th International Conference on Semantic Systems, SEMANTICS, 25-32.

Suarta I. M., Suwintana I. K., Sudhana I. F. P., \& Hariyanti N. K. D. (2018) Employability skills for entry level workers: a content analysis of job advertisements in Indonesia, Journal of Technical Education and Training, 10 (2), 49-61.

Whiddett, S., \& Hollyforde, S. (2007). Competencies. London: CIPD. 


\section{Interinational Quality Conferencen}

Pawel Lula

Cracow University of

Economics,

Cracow,

Poland

pawel.lula@uek.krakow.p 1

Anna Kovaleva

Saint-Petersburg State

University of Economics,

Saint-Petersburg,

Russia

intermasterf@gmail.com

\section{Renata Oczkowska}

Cracow University

Economics,

Cracow,

Poland

renata.oczkowska@uek.krakow. $\mathrm{pl}$

\section{Sylwia Wiśniewska}

of Cracow University of Economics, Cracow,

Poland

sylwia.wisniewska@uek.krakow. pl 